\title{
What's a reader \\ actually worth?
}

\section{Neil Tburman}

\section{Cash-strapped publishers should measure audiences in new ways to show the true palue they deliver to advertisers}

The audience metrics used by the journalism industry are important. They can tell us not only about the journalism that audiences value, but also about the audiences that journalism values. This article is about how audiences for newspapers are measured and how they could be measured, and shows how new measurement methods can change our understanding of readers' relationship with the news.

Audience metrics are the fuel of the audience marketplace. Audiences are generated by media producers and sold to advertisers. This is big business, worth about $\$ 500$ billion a year. Media measurement firms play a significant role, producing or auditing audience data that can determine the success or failure of media outlets. Without the right quantity or quality of "measured" audience to sell to advertisers, a media outlet's days are numbered. The ways in which audiences are measured, therefore, help determine the level and price of advertising publishers can attract and thus what sort of journalism the market delivers.

With newspaper brands, the difficult financial position that many find themselves in means the methods used to measure their audiences, and the data produced, are of particular concern. And the fact that they publish both in print and online makes the measurement of their total audience a particular challenge.

Newspapers' audience metrics have evolved little over the years. In terms of their print channels, circulation has been reported for centuries and readership for decades. In terms of their online channels, the main 
metrics, again, have long remained unchanged - unique users and page impressions. If we put these audience measures side by side we can see some problems. First, online and print audiences have mostly been measured over different and fundamentally incomparable time periods - on a daily or weekly basis for print newspapers and monthly for online.

Second, there's the problem of duplication. The print and online audience numbers can't be added together because there's a large overlap between the audience segments. There have been moves by the industry to eliminate these incompatibilities but they have come, only recently and in a way that tends to perpetuate the false equivalence between print and online reading.

So why have newspapers been so slow to produce audience data that is comparable across platforms? Probably because the traditional metrics have supported a convenient narrative: that though newspapers' print circulations have been in decline, they have been building large online audiences that will carry them forward into the future. For example, in 2011 The Guardian reported an average British readership per Monday to Saturday print issue of $1,120,000$ but a much larger monthly UK online audience: 18,297,426 unique browsers.

In the past few years, however, we've seen moves to start to eliminate audience duplication from the data and to measure print and online audiences over the same time period. For example, in the UK and elsewhere traditional print readership data is starting to be fused with data about internet audiences. Typically, print readership continues to be measured in the traditional way, using home interviews or surveys. Internet audiences are usually measured passively with software meters and tagging. Fusing the two data sets leads to the removal of duplicates, among other things. But while new methodologies like this are an improvement, the data they produce is misleading because there is an implicit assumption that one print reader has the same value as one online reader. Print and online readers, however, are very different in the amount of attention they give to newspaper brands.

So how is data from one of the new hybrid methodologies - PADD developed by the UK National Readership Survey (NRS) being presented by the industry? It's being used to show how online adds to newspapers' audiences in terms of extra reach or exposure. Indeed, Katherine Page from the National Readership Survey wrote that the inclusion of online data has "created impressive headlines about the overall reach of publishers", and 
talked about how this new data had transformed depressing headlines about the ongoing decline of print audiences into positive stories of "growing mobile audiences and extensive brand reach".

The problem with this focus on reach is that it continues what Leo Bogart, the American sociologist and media expert, has criticised as a preoccupation with audience size, which, he says, can lead to bad media management decisions. Reach as a metric tells us only that an audience member has seen a media outlet. It doesn't tell us anything about levels of attention or engagement. But we're now seeing what might be the beginnings of a trend towards attention-based measures - in particular time spent - replacing reach as the primary reporting metric.

For example, Ofcom believes that "share of consumption" should be "calculated from time spent as measured by the industry measurement systems". The Financial Times believes "time-based metrics will benefit publishers" because they value "real reader engagement over clicks". And the online publishing platform Medium, developed by Twitter's co-founder Ev Williams, uses "total time reading" as its "top-line metric" because Williams believes it is "dumb" to try to measure the success of a website or app based simply on the "number of people who have used it" over a given period.

\section{Not reach but time spent}

So what if it were possible to combine newspapers' official print and online audience data sets with the aim of finding out not about reach but about time spent reading? Looking at the consumption of newspaper brands by time spent could change our understanding of the value that audiences give to different newspaper brands and distribution platforms. I decided to do just that using a sample of 11 British national newspaper brands.

Data on time spent reading is available from the NRS and comScore for newspapers' print, web, and mobile audiences. The data on mobile audiences, it's worth noting, became available only in the past two years. Before then it wasn't possible to accurately and comprehensively track the behaviour of newspapers' mobile audiences.

What do the results show us about the journalism that audiences value? They show us just how much more engaging journalism is in print than online. Of the time spent with the newspaper brands by their national audiences over a year, about 88 per cent is still in print and only about 
11 per cent online. About 4 per cent comes from PC usage and about 7.5 per cent from mobile:

\section{Aggregated time spent reading (billions of minutes/year) by news brands'} British audiences aged 18 and over

\begin{tabular}{lcccc} 
& PRINT & PC & MOBILE & TOTAL \\
\hline Mail & 60.90 & 6.44 & 11.09 & $\mathbf{7 8 . 4 4}$ \\
\hline Sun & 50.36 & 0.28 & 0.86 & $\mathbf{5 1 . 5 0}$ \\
\hline Telegraph & 27.07 & 1.42 & 1.52 & $\mathbf{3 0 . 0 0}$ \\
\hline Mirror & 25.19 & 0.58 & 1.67 & $\mathbf{2 7 . 4 4}$ \\
\hline Times & 26.59 & 0.06 & 0.41 & $\mathbf{2 7 . 0 6}$ \\
\hline Guardian & 14.75 & 1.54 & 3.47 & $\mathbf{1 9 . 7 5}$ \\
\hline Express & 11.82 & 0.22 & 0.26 & $\mathbf{1 2 . 2 9}$ \\
\hline Star & 8.99 & 0.13 & 0.26 & $\mathbf{9 . 3 8}$ \\
\hline Record & 6.18 & 0.05 & 0.26 & $\mathbf{6 . 4 9}$ \\
\hline Herald & 1.98 & 0.02 & 0.03 & $\mathbf{2 . 0 4}$ \\
\hline Scotsman & 1.27 & 0.04 & 0.06 & $\mathbf{1 . 3 7}$ \\
\hline $\begin{array}{l}\text { Data is for April 2015 to March 2016 (inclusive) and from the NRS for print and } \\
\text { comScore for online. Mobile reading time excludes video viewing. }\end{array}$ \\
\hline
\end{tabular}

We also see that, while print editions in my sample are read for an average of 40 minutes per reader per day, online editions are consumed for less than 30 seconds per user per day:

\begin{tabular}{lcc}
\hline & $\begin{array}{c}\text { DAILY PRINT READING TIME, } \\
\text { PER READER (MINUTES) }\end{array}$ & $\begin{array}{c}\text { DAILY ONLINE MINUTES } \\
\text { PER VISITOR PER DAY }\end{array}$ \\
\hline Mail & $43: 00$ & $2: 00$ \\
\hline Guardian & $39: 00$ & $0: 41$ \\
\hline Sun & $32: 00$ & $0: 40$ \\
\hline Mirror & $37: 00$ & $0: 21$ \\
\hline Record & $31: 00$ & $0: 19$ \\
\hline Times & $47: 00$ & $0: 17$ \\
\hline Telegraph & $53: 00$ & $0: 17$ \\
\hline Star & $31: 00$ & $0: 16$ \\
\hline Express & $39: 00$ & $0: 12$ \\
\hline Scotsman & $38: 00$ & $0: 10$ \\
\hline Herald & $50: 00$ & $0: 09$ \\
Average & $50: 00$ & $0: 29$
\end{tabular}

The online data, from comScore, is for March 2016 and for the UK. The print data (from the NRS) is an average for the period April 2015 to March 2016, relates to Monday to Friday editions and is for Great Britain.

So how does newspaper consumption as time spent change our 
time spent. But on time spent its popularity is even more pronounced. The Sun also ranks more highly. But we see falls for The Guardian and the Daily Mirror. What does all this signify?

First, the results raise questions about allocation of resources across different platforms. Although newspapers have spent decades investing in digital distribution, online channels are not attracting anywhere near the levels of attention commanded by print. Iris Chyi, at the University of Texas, says newspapers are "stuck between a failing experiment with digital and a shrinking market for print". And she's not the only one to be thinking that way.

I'm afraid I can't offer many solutions. There are wider structural issues contributing to newspapers' decline, such as the many more sources of news available today. However, the results are a reminder of the inherent qualities of paper as a reading medium and the effectiveness of newspaper design conventions refined over centuries. Newspapers might profit from harnessing these qualities rather than simply chasing reach.

And the new insights are timely. In the case of the UK, they show more conservative and popularist tastes than the standard metrics do. To understand things like the dynamics behind Brexit we should look at audience data that reflects attention, not simply reach. The results should also alarm media regulators. By time spent, the Daily Mail has a 30 per cent share of the UK national newspaper market. Many people would say that was too much.

The reluctance of the industry to embrace attention-based metrics reveals something about the audiences that journalism values. Big audiences have mostly trumped attentive audiences. In part, this may be because that's what advertisers have wanted. It's certainly because it's been easier to build reach in the digital age than to build attention. But the preoccupation with size has led to some erroneous management decisions.

Attention-based metrics also have limitations. They reflect the length of audience engagement, not appreciation, recall or action taken. For newspapers, however, reporting audience via time spent would be a way of capturing the character of multiplatform consumption. It also produces a single number that's easy to understand. And the data is available right now.

Neil Thurman is professor of communication at Ludwig-Maximilians University in Munich and a Volkswagen Foundation Freigeist fellow. 